\section{Transferability of Microsatellite Markers across Eleven Species of Magnolia L.}

\author{
Chandra S. Thammina ${ }^{1}$
}

USDA-ARS U.S. National Arboretum, Floral and Nursery Plants Research Unit, 10300 Baltimore Avenue, Building 010A, Beltsville, MD 20705; Department of Plant Biology and Pathology, Rutgers University, 59 Dudley Road, New Brunswick, NJ 08901

Christopher von Kohn and Margaret R. Pooler ${ }^{2}$ USDA-ARS U.S. National Arboretum, 3501 New York Avenue, NE, Washington, DC 20002

Additional index words. conservation, germplasm characterization, Magnoliaceae, simple sequence repeat

\begin{abstract}
The genus Magnolia (Magnoliaceae) comprises more than 130 species distributed predominantly in temperate and tropical regions in Southeast Asia and is valued worldwide for its ornamental traits as well as for timber and medicinal products, and in trade. Despite their favored status, many species of Magnolia are faced with threats from logging, agricultural land use, development, and collection, and are at risk of extinction. Conservation of these species through habitat preservation and in ex situ collections is needed to prevent extinction. To provide a tool for conservation of Magnolia species, microsatellite markers developed previously for Magnolia ashei were tested in 10 other species of Magnolia to determine their transferability across species. Of the 64 primer pairs tested, 21 amplified alleles in the expected size range in all samples; 11 primer pairs amplified clean products in most, but not all, species; 18 primer pairs consistently amplified a polymerase chain reaction (PCR) product in most species, but had either low peak height or other amplification issues; and 14 primers showed excessive stutter, nonspecific amplification, or no amplification. Cluster analysis using the 129 alleles amplified by these 21 simple sequence repeat (SSR) primer pairs generated groups that corresponded to the known taxonomic relationships in this genus.
\end{abstract}

Magnolia L. (Magnoliaceae) is a popular genus comprising more than 130 species distributed predominantly in temperate and tropical regions in Southeast Asia (Azuma et al., 1999; Figlar and Nooteboom, 2004; Kim et al., 2001). They are valued worldwide for their ornamental traits as well as for timber and medicinal products, and in trade, and are well recognized botanically as one of the earliest flowering plants (Raven et al., 1986). Despite their favored status, many species of Magnolia are faced with threats from logging, agricultural land use, development, and collection, and are at risk of extinction. According to a recent study by Botanic Gardens Conservation International (BGCI), $48 \%$ of the species studied are

Received for publication 24 Sept. 2018. Accepted for publication 19 Nov. 2018.

The mention of trade names or commercial products in this article is solely for the purpose of providing specific information and does not imply recommendations or endorsement by the U.S. Department of Agriculture.

${ }^{1}$ Current address: Irrigated Agriculture Research and Extension Center, Washington State University, 24106 N. Bunn Road, Prosser, WA 99350.

${ }^{2}$ Corresponding author. E-mail: Margaret.Pooler@ ars.usda.gov.
Microsatellite markers, or SSRs, are an efficient method to assess the genetic dipopulations [Powell et al. (1996); reviewed in Varshney et al. (2005); Wang et al. (2009)], and have proved useful for guiding conservation efforts in several Magnolia species, including M. ashei Weath. (von Kohn et al., 2018), M. obovata Thunb. (Isagi et al., 1999), M. stellata (Seibold \& Zucc.) Maxim. (Ueno et al., 2005), M. sieboldii K. Koch (Kikuchi and Isagi, 2002), M. tripetala (L.) L. (Gilkison, 2013), M. sharpii Miranda, and $M$. schiedeana Schltdl. (Newton et al., 2008), among others. The availability of additional SSR markers that are useful in multiple Magnolia species could facilitate the characterization of threatened species for ex situ conservation. The objective of this study was to determine the transferability of genomic SSR primers developed for $M$. ashei (von Kohn et al., 2018) to 10 additional Magnolia species to provide a tool for population and conservation studies.

\section{Materials and Methods}

Plant material. Shoot tips from 22 samples representing 11 Magnolia species (Table 1) were collected or sent from cooperators and refrigerated before DNA extraction. Genomic DNA was extracted from 0.040 to $0.100 \mathrm{~g}$ vegetative buds using a PowerPlant Pro DNA Isolation Kit (MoBio Laboratories, Inc., Carlsbad, CA) according to the manufacturer's instructions with the following modifications: the addition of a Vista, CA) to aid in homogenization, inclusion of the optional phenolic separation solution, and an additional wash step before elution. DNA was quantified using a NanoDrop 1000 Spectrophotometer (Thermo

$S S R$ primer evaluation and PCR. Genomic SSR primers were developed and selected from Magnolia ashei as described versity and population structure of plant small amount of garnet matrix (BIO 101, Inc. Fisher Scientific, Wilmington, DE).

Table 1. List of 11 Magnolia species used in this study, including section, ploidy, number of samples per species tested, and source of samples.

\begin{tabular}{|c|c|c|c|c|}
\hline Species $^{z}$ & Section $^{z}$ & Ploidy $^{\mathrm{y}}$ & $\begin{array}{c}\text { No. of } \\
\text { samples } \\
\text { tested }\end{array}$ & Sources $^{\mathrm{x}}$ (accession no.) \\
\hline M. acuminata (L.) L. & Yulania & $4 x$ & 3 & $\begin{array}{l}\text { UCBG (94.0923); MA (35-91*3); } \\
\text { ABG (var. subcordata) }\end{array}$ \\
\hline M. ashei Weath. & Macrophylla & $2 x$ & 3 & USNA (NA81565, 81555, 81560) \\
\hline M. dealbata Zucc. & Macrophylla & $2 x$ & 2 & UCBG $(86.0507)$ \\
\hline M. fraseri Walter & Auriculata & $2 x$ & 2 & ABG; UCBG (82.2174) \\
\hline M. guatemalensis Donn.Sm. & Magnolia & $2 x$ & 2 & UCBG (72.0658) \\
\hline M. macrophylla Michx. & Macrophylla & $2 x$ & 2 & USNA (leaf material from Alabama) \\
\hline M. pyramidata $\mathrm{W}$. Bartram & Auriculata & $2 x$ & 2 & USNA (leaf material from Florida) \\
\hline M. sharpii Miranda ${ }^{\mathrm{x}}$ & Magnolia & $2 x$ & 1 & UCBG (81.0939) \\
\hline M. tamaulipana A. Vázquez ${ }^{\mathrm{x}}$ & Magnolia & $6 x$ & 2 & UCBG $(91.0683 ; 91.1423)$ \\
\hline M. tripetala (L.) L. & Rytidospermum & $2 x$ & 2 & ABG; MA (164-2001*1) \\
\hline M. virginiana $\mathrm{L}$. & Magnolia & $2 x$ & 1 & MA $(1-98 * 2)$ \\
\hline
\end{tabular}

${ }^{\mathrm{z}}$ Species authority and classification are according to the U.S Department of Agriculture, Agricultural Research Service (2018) and Kim and Suh (2013). All species are in subgenus Magnolia except $M$. acuminata, which is in subgenus Yulania (Spach) Rchb.

${ }^{\text {y }}$ Ploidy based on Parris et al. (2010).

${ }^{\mathrm{x}} M$. sharpii and M. tamaulipana are classified as endangered (Rivers et al., 2016).

$\mathrm{ABG}=$ Atlanta Botanical Garden-Gainesville; $\mathrm{MA}=$ Morton Arboretum; UCBG = University of California Botanical Garden; USNA = U.S. National Arboretum. 


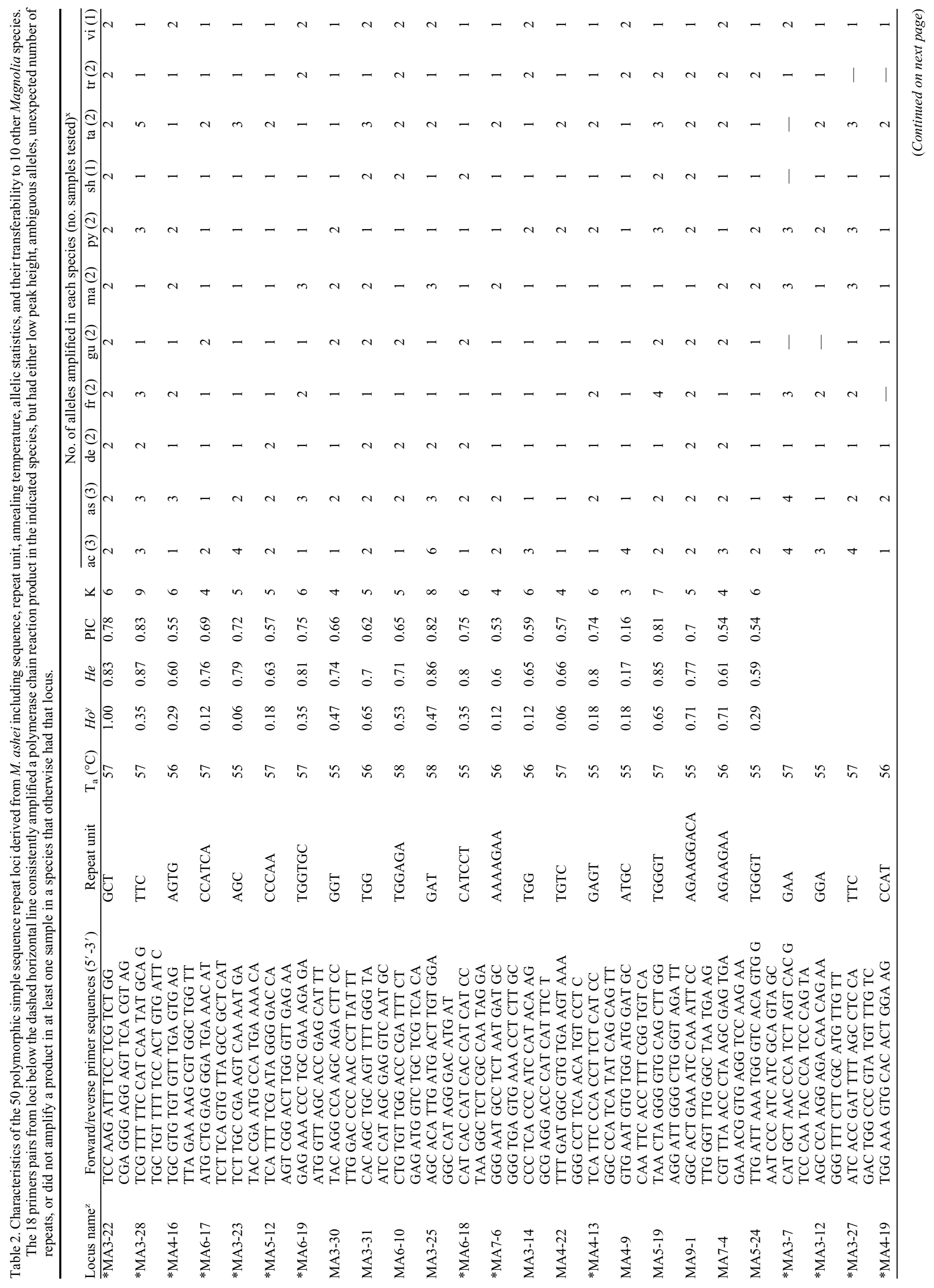




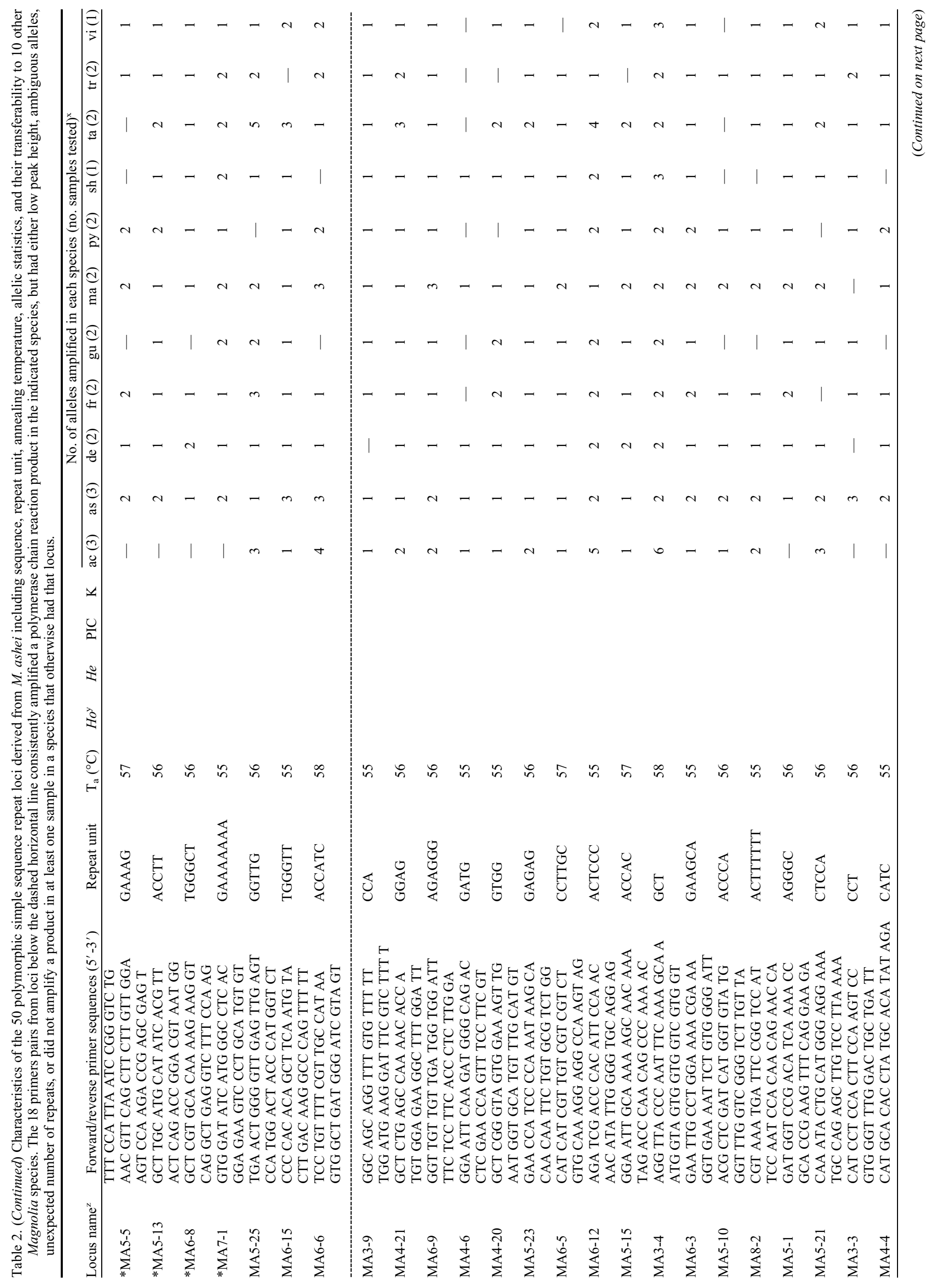




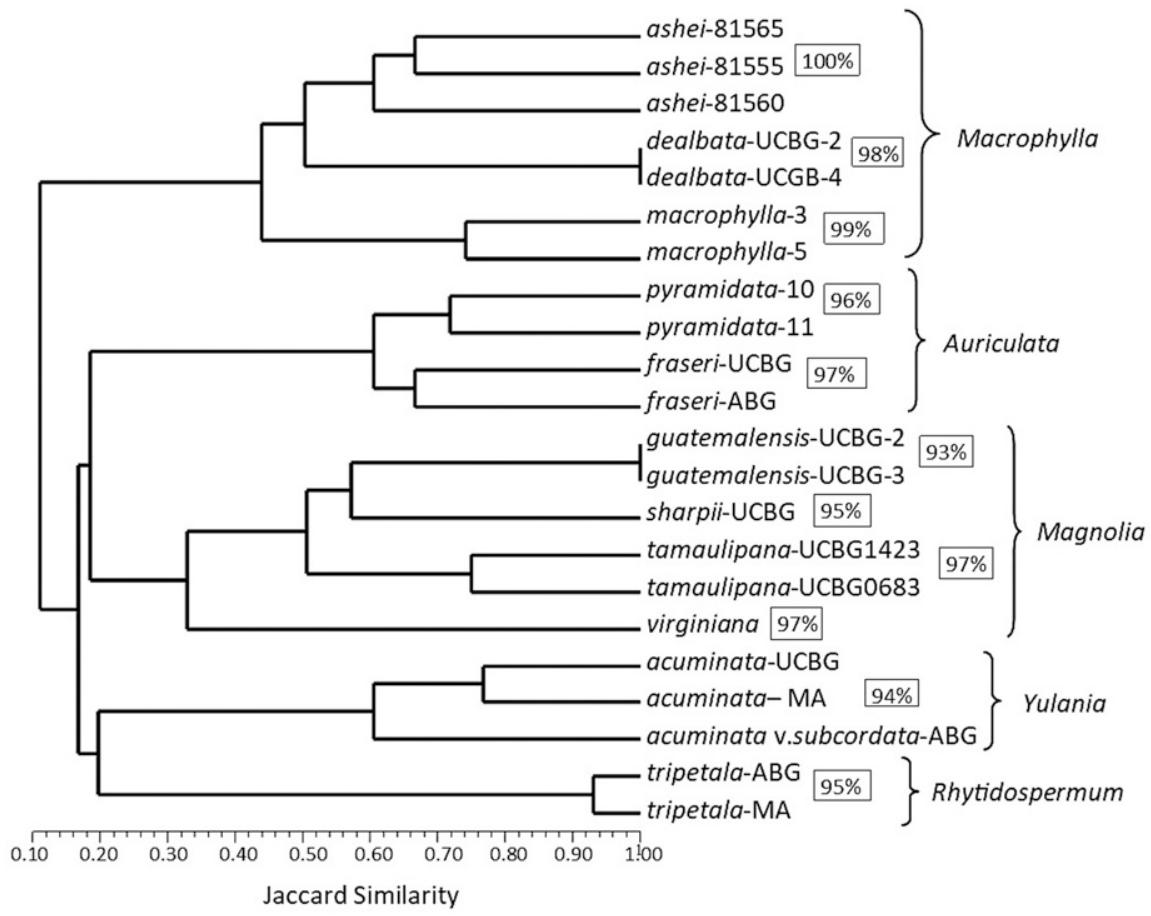

Fig. 1. Unweighted pair group method with arithmetic mean dendrogram of 22 Magnolia samples based on Jaccard similarity data from 129 alleles from 21 simple sequence repeats loci. Numbers in boxes indicate the percentage of $M$. ashei primers that amplified a product in each species (of 50 primers listed in Table 2). Names following braces indicate the taxonomic section to which the species belongs. Cophenetic correlation coefficient $(r)=0.982$.

in von Kohn et al. (2018). Briefly, SSRs were identified from Illumina sequence data (deposited in GenBank, accession no. PCNC00000000) using the MIcroSAtellite identification tool (Beier et al., 2017). Primers for 64 SSR loci with differing repeat units (Table 2) were identified using Primer 3 Plus (Untergasser et al., 2012). PCR primers were manufactured by Integrated DNA Technologies (Coralville, IA). The forward primers had an additional M13 (-21) universal sequence (TGTAAAACGACGGCCAGT) attached to the $5^{\prime}$ end to allow indirect fluorescent labeling of PCR products using a universal 6-carboxy-fluorescine (FAM)labeled M13 primer (Schuelke, 2000). PCR was carried out in a Bio-Rad T100 Thermal Cycler (Bio-Rad Laboratories, Inc., Hercules, CA). The 15- $\mu \mathrm{L}$ PCR mixture contained $30 \mathrm{ng}$ template genomic DNA, $0.25 \mu \mathrm{M}$ of each reverse and universal FAM-labeled M13 (-21) primer, and $0.0625 \mu \mathrm{M}$ of the forward primer with $1 \times$ Bioline MangoMix and $3.77 \mathrm{~mm}$ Bioline $\mathrm{MgCl}_{2}$ (Bioline Inc., Taunton, MA). PCR profiles consisted of initial denaturation at $94{ }^{\circ} \mathrm{C}$ for $5 \mathrm{~min}$; followed by 30 cycles of $94{ }^{\circ} \mathrm{C}$ for $30 \mathrm{~s}$, optimized annealing temperature of each primer pair (Table 2) for $30 \mathrm{~s}$, and $72{ }^{\circ} \mathrm{C}$ for $60 \mathrm{~s}$; followed by eight cycles of $94{ }^{\circ} \mathrm{C}$ for $30 \mathrm{~s}, 53{ }^{\circ} \mathrm{C}$ for $45 \mathrm{~s}$, and $72{ }^{\circ} \mathrm{C}$ for $45 \mathrm{~s}$; and a final extension at $72{ }^{\circ} \mathrm{C}$ for $10 \mathrm{~min}$. Products were analyzed on an ABI 3730xl DNA Analyzer (Applied Biosystems, Foster City, CA) using $2 \mu \mathrm{L}$ PCR product, $10 \mu \mathrm{L}$ formamide (Applied Biosystems), and $0.2 \mu \mathrm{L}$ GeneScan 500 LIZ Size Standard (Applied Biosystems). Allele sizes and number of alleles per locus were determined with GeneMarker version 2.6.3 (SoftGenetics, State College, PA). Reactions that resulted in unexpected, ambiguous, low, or no amplification were repeated.

Data analysis. Allele frequency analysis for 21 loci that showed consistent and predicted amplification products in all samples tested was performed using Cervus 3.0.7 (Kalinowski et al., 2007), based on allelic data from the 17 diploid samples (Table 1). Data from these 21 loci for all species were converted to a binary matrix (presence/ absence of allele) and used to generate a similarity matrix based on the Jaccard coefficient using NYSYSpc version 2.02 (Rohlf, 1998). Accessions were then clustered using the unweighted pair group method with arithmetic mean (UPGMA) algorithm in NTSYSpc. Cophenetic matrices were constructed and compared with the similarity matrices using the MXCOMP program to test the goodness of fit of a cluster (Rohlf, 1998)

\section{Results}

Of the 64 primer pairs tested, 21 amplified alleles in the expected size range in all samples of all 11 species tested (Table 2). Eleven primer pairs amplified clean products in most, but not all, species. An additional 18 primer pairs (below the dashed horizontal line in Table 2) consistently amplified a PCR product in the indicated species, but had either low peak height, ambiguous alleles, unexpected size of the repeated unit, or did not amplify a product in at least one sample in 
a species that otherwise had that locus. Finally, the remaining 14 primers (not listed) showed excessive stutter, nonspecific amplification, or no amplification.

A total of 129 alleles were scored from the 21 primer pairs that resulted in "complete" data. Allelic data from the 17 diploid samples were used to calculate allelic frequencies and polymorphic information content (PIC) for these 21 loci. PIC values ranged from 0.16 to 0.83 (Table 2). The 129 alleles were also used to generate a UPGMA dendrogram based on the Jaccard similarity coefficient (Fig. 1). Although the purpose of this study was not to confirm interspecific diversity or taxonomic classification in Magnolia, the phenogram provides strong evidence that the primers developed in M. ashei are representative of the allelic diversity in the genus. The cophenetic correlation coefficient for the dendrogram was 0.982 , indicating that the dendrogram is a very good fit to the data set (Rohlf, 1998). Equally significant, the major clusters in the dendrogram followed the taxonomic relationships reported previously (Figlar and Nooteboom, 2004; Kim et al., 2001; Kim and Suh, 2013). Specifically, all samples grouped together by species, and all species clustered together by section (Table 1).

\section{Discussion}

Many studies have reported the utility and limitations of cross-species amplification of SSR primers in plants [e.g., reviewed by Barbara et al. (2007), Varshney et al. (2005), Wang et al. (2009)]. As would be expected and has been confirmed in other studies, the success of SSR primer transferability across species is correlated with how closely related the species are (Bruegmann and Fladung, 2013; Buzatti et al., 2016). We observed similar results in our study (Fig. 1), in which only one primer did not amplify in $M$. macrophylla Michx. and two primers did not amplify in M. dealbata Zucc. (Table 2), both of which are in the same section (sec. Macrophylla Figler \& Noot.) as M. ashei (Table 1). Conversely, an average of 5.75 primers did not amplify in species outside the section.

The real test of how useful SSR markers will be in related species or genera is not whether they amplify, but how polymorphic the markers are (Barbara et al., 2007). Because our study used only one to three samples of each species, it is not possible to determine whether the SSR loci that showed only one allele in a species are truly monomorphic in that species. Some studies indicate that genomic SSRs may have more nonspecific amplification or stuttering than genic SSRs (Varshney et al., 2005), although they may be more polymorphic in closely related accessions [such as within a species (Song et al., 2012)]. The SSRs described here were developed to study population structure within one species (M. ashei) and were derived from genomic DNA, so they may prove to be less polymorphic, less transferable, or less clearly amplified in more distantly related taxa. Comparative studies indicate that successful cross-species amplification and polymorphism are more likely within genera such as Magnolia, which are perennial (vs. annual) and are outcrossing (vs. selfing) (Barbara et al., 2007).

The SSR primers reported in this article and those from other Magnolia studies contribute to an increasingly valuable set of tools to gather genetic and population data on Magnolia species. Of the 304 Magnoliaceae species studied in the 2016 BGCI report, 20\% could not be assessed as a result of a lack of data. As development of SSR markers becomes more economical (Zalapa et al., 2012), it may be feasible to develop markers specifically for data-deficient species with pressing conservation needs. However, in many cases, especially when quick action is needed and resources are limited, the use of SSR markers developed for other species will be critical in obtaining sufficient data to guide effective conservation of threatened species. The Global Strategy for Plant Conservation, adopted as part of the Convention on Biological Diversity in 2002 , includes as one of its targets the conservation of at least $75 \%$ of the world's threatened plants in ex situ collections by 2020 (Hird and Kramer, 2013). Currently, only $43 \%$ of threatened Magnolia species are preserved in ex situ collections (Rivers et al., 2016). Many Magnolia species have recalcitrant seeds, so must be conserved via resource- and space-intensive plantings. Data derived from SSR markers can be used to determine population structure or genetic diversity, which enables maximizing the amount of genetic diversity held in ex situ collections while minimizing the number of individuals required. This information will allow curation of ex situ collections to capture and reflect the genetic diversity of the wild populations (Cires et al., 2013; IUCN/SSC, 2014; Rivers et al., 2016). The SSR primers described here provide a valuable tool for developing conservation strategies for this important genus.

\section{Literature Cited}

Azuma, H., L.B. Thien, and S. Kawano. 1999. Molecular phylogeny of Magnolia (Magnoliaceae) inferred from cpDNA sequences and evolutionary divergence of the floral scents. J. Plant Res. 112:291-306.

Barbara, T., C. Palma-Silva, G.M. Paggi, F. Bered, M.F. Fay, and C. Lexer. 2007. Crossspecies transfer of nuclear microsatellite markers: Potential and limitations. Mol. Ecol. 16:3759-3767.

Beier, S., T. Thiel, T. Münch, U. Scholz, and M. Mascher. 2017. MISA-web: A web server for microsatellite prediction. Bioinformatics 33: 2583-2585.

Bruegmann, T. and M. Fladung. 2013. Potentials and limitations of the cross-species transfer of nuclear microsatellite makers in six species belonging to three sections of the genus Populus L. Tree Genet. Genomes 9:14131421.

Buzatti, R.S.O., F.S.L. Chicata, and M.B. Lovato. 2016. Transferability of microsatellite markers across six Dalbergia (Fabaceae) species and their characterization for Dalbergia miscolobium. Biochem. Syst. Ecol. 69:161-165.

Cires, E., Y. DeSmet, G. Cuesta, P. Goetghebeur, S. Sharrock, D. Gibbs, S. Oldfield, A. Kramer, and M. Samain. 2013. Gap analyses to support ex situ conservation of genetic diversity in Magnolia, a flagship group. Biodivers. Conserv. 22:567-590.

Figlar, R.B. and H.P. Nooteboom. 2004. Notes on Magnoliaceae IV. Blumea 49:87-100.

Gilkison, V.A. 2013. Comparisons of genetic diversity among disjunct populations of Magnolia tripetala. Honors project thesis, Western Kentucky University. 17 Sept. 2018. <http://digitalcommons.wku. edu/stu_hon_theses/423>.

Hird, A. and A.T. Kramer. 2013. Achieving target 8 of the global strategy for plant conservation: Lessons learned from the North American collections assessment. Ann. Mo. Bot. Gard. 99:161-166.

Isagi, Y., T. Kanazashi, W. Suzuki, H. Tanaka, and T. Abe. 1999. Polymorphic microsatellite DNA markers for Magnolia obovata Thunb. and their utility in related species. Mol. Ecol. 8:685-702.

IUCN/SSC. 2014. Guidelines on the use of ex situ management for species conservation. Version 2.0. IUCN Species Survival Commission, Gland, Switzerland. 18 Sept. 2018. <https:// portals.iucn.org/library/sites/library/files/documents/ 2014-064.pdf>.

Kalinowski, S.T., M.L. Taper, and T.C. Marshall. 2007. Revising how the computer program CERVUS accommodates genotyping error increases success in paternity assignment. Mol. Ecol. 16:1099-1106.

Kikuchi, S. and Y. Isagi. 2002. Microsatellite genetic variation in small and isolated populations of Magnolia sieboldii ssp. japonica. Heredity 88:313-321.

Kim, S., C.W. Park, Y.D. Kim, and Y. Suh. 2001. Phylogenetic relationships in family Magnoliaceae inferred from NDHF sequences. Amer. J. Bot. 88:717-728.

Kim, S. and Y. Suh. 2013. Phylogeny of Magnoliaceae based on ten chloroplast DNA regions. J. Plant Biol. 56:290-305.

Newton, A.C., J. Gow, A. Robertson, G. WilliamsLinera, N. Ramírez-Marcial, M. GonzálezEspinosa, T.R. Allnutt, and R. Ennos. 2008. Genetic variation in two rare endemic Mexican trees, Magnolia sharpii and Magnolia schiedeana. Silvae Genet. 57:348-356.

Parris, J.K., T.G. Ranney, H.T. Knap, and W.V. Baird. 2010. Ploidy levels, relative genome sizes, and base pair composition in Magnolia. J. Amer. Soc. Hort. Sci. 135:533-547.

Powell, W., G.C. Machray, and J. Provan. 1996. Polymorphism revealed by simple sequence repeats. Trends Plant Sci. 1:215-222.

Raven, P.H., R.F. Evert, and S.E. Eichhorn. 1986. Biology of plants. 4th ed. Worth Publishers, New York, NY.

Rivers, M., E. Beech, L. Murphy, and S. Oldfield. 2016. The red list of Magnoliaceae. Botanic Gardens Conservation International, Surrey, UK.

Rohlf, F.J. 1998. NTSYS-pc 2.02: Numerical taxonomy and multivariate analysis system. Exeter Software, Applied Biostatistics Inc., Setauket, New York, NY.

Schuelke, M. 2000. An economic method for the fluorescent labeling of PCR fragments. Nat. Biotechnol. 18:233-234.

Song, Y.P., X.B. Jiang, M. Zhang, Z.L. Wang, W.H. Bo, X.M. An, D.Q. Zhang, and Z.Y. Zhang. 2012. Differences of EST-SSR and genomic-SSR markers in assessing genetic diversity in poplar. For. Stud. China 14:1-7.

Ueno, S., S. Setsuko, T. Kawahara, and H. Yoshimaru. 2005. Genetic diversity and differentiation of the endangered Japanese endemic tree Magnolia stellata using nuclear and 
chloroplast microsatellite markers. Conserv. Genet. 6:563-574.

Untergasser, A., I. Cutcutache, T. Koressaar, J. Ye, B.C. Faircloth, M. Remm, and S.G. Rozen. 2012. Primer3: New capabilities and interfaces. Nucl. Acids Res. 40:E115.

U.S Department of Agriculture, Agricultural Research Service. 2018. U.S. National Plant Germplasm System: GrinGlobal version 1.9.7.1.
18 Sept. 2018. <https://npgsweb.ars-grin.gov/ gringlobal/taxon/taxonomysearch.aspx $>$.

Varshney, R.K., A. Graner, and M.E. Sorrells. 2005. Genic microsatellite markers in plants: Features and applications. Trends Biotechnol. 23:48-55. von Kohn, C., K. Conrad, M. Kramer, and M. Pooler. 2018. Genetic diversity of Magnolia ashei characterized by SSR markers. Conserv. Genet. 19:923-936.
Wang, M.L., N.A. Barkley, and T.M. Jenkins. 2009. Microsatellite markers in plants and insects. Part I: Applications of biotechnology. Genes Genomes Genomics 3:54-67.

Zalapa, J.E., H. Cuevas, H. Zhu, S. Steffan, D. Senalik, E. Zeldin, B. McCown, R. Harbut, and P. Simon. 2012. Using next-generation sequencing approaches to isolate simple sequence repeat (SSR) loci in the plant sciences. Amer. J. Bot. 99:193-208. 